\title{
Petit portrait du télégraphe en traducteur
}

Loïc Riom

\section{(2) OpenEdition}

\section{Journals}

Édition électronique

URL : http://journals.openedition.org/itti/346

DOI : $10.4000 /$ itti.346

\section{Éditeur}

Université de Poitiers

\section{Référence électronique}

Loïc Riom, «Petit portrait du télégraphe en traducteur », Images du travail, travail des images [En ligne] 8 | 2020, mis en ligne le 01 février 2020, consulté le 14 avril 2021. URL : http:// journals.openedition.org/itti/346 ; DOI : https://doi.org/10.4000/itti.346

Ce document a été généré automatiquement le 14 avril 2021.

Images du travail, travail des images 


\title{
Petit portrait du télégraphe en traducteur
}

\author{
Loïc Riom
}

Ce court texte est issu d'une enquête collectivement menée au sein de l'Unité de sociologie visuelle de l'Université de Genève. Je tiens à remercier mes collègues - Solène Gouilhers, Cornelia Hummel, Leah Kimber, Michaël Meyer et Irina Radu - pour le travail collectif effectué ainsi que pour leurs précieux retours sur la première version de ce texte. Je remercie également les évaluateur.trice.s de la revue pour leurs commentaires.

Photo 1 : Le télégraphe sur la passerelle de pilotage

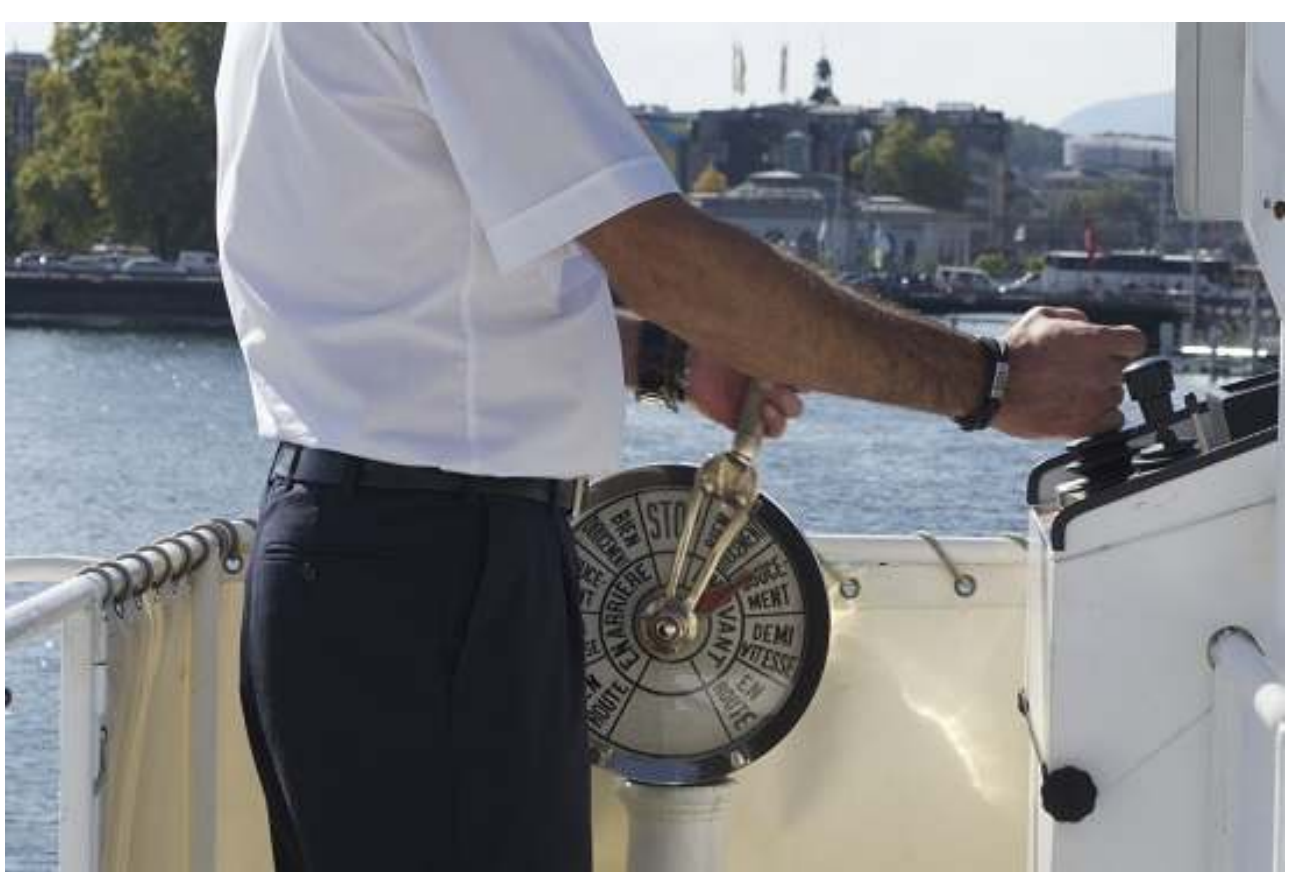

Source : Cornelia Hummel 
1 Pour commencer, le décor : un bateau à vapeur de la flotte Belle Epoque du lac Léman. Ensuite, les acteurs : en haut, sur la passerelle, le capitaine; en bas, dans la salle des machines, le mécanicien; entre ces deux mondes, un système de communication mécaniquement actionné par câbles, le télégraphe. Cet attelage d'un genre étrange est, encore aujourd'hui ${ }^{1}$, la colonne vertébrale du vapeur.

2 Les photos permettent de suivre les ramifications de ce dispositif sociotechnique et de rendre compte de son fonctionnement lors des manœuvres. En haut, sur la passerelle, le capitaine actionne la poignée du télégraphe pour indiquer la vitesse désirée sur son cadran (photo 1). En bas, l'aiguille du cadran de la salle des machines se déplace sur la vitesse indiquée (photo 2). Le mécanicien répond alors que l'«ordre» a bien été « reçu » et donne la « quittance » en plaçant sa poignée sur le cadran indiqué. Celle-ci fait pivoter, en retour, l'aiguille rouge du cadran de la passerelle (photo 1 et 2). La façon d'actionner la poignée - d'un mouvement sec ou progressif - renseigne sur la célérité d'exécution de l'ordre attendue par le capitaine. Plus que simplement transmettre une indication écrite, le mécanisme du télégraphe augmente l'information échangée entre le pilotage et la salle des machines.

3 Ce double mouvement, d'abord vers le bas, puis vers le haut (à la fois dans l'architecture du bateau, mais également dans sa hiérarchie), permet de «traduire » terme utilisé par le capitaine - son appréciation visuelle en vitesse effective. Au-delà du sourire que le sociologue ne peut retenir à l'utilisation de ce terme pas complètement étranger à son propre vocabulaire, que permet-il de saisir sur le fonctionnement du travail à bord? Traduire, c'est attacher solidement des actants ensemble (Latour, 2005) : exactement ce que fait le télégraphe. "C'est comme dans une voiture : en haut, c'est le volant; ici, ce sont les pédales " explique le mécanicien. Le capitaine n'a absolument aucune prise directe sur la machine à vapeur et donc la vitesse du bateau. Seul le mécanicien peut le faire en réglant la pression distribuée dans les pistons, mais celui-ci n'a aucune visibilité. Pour le capitaine comme pour le mécanicien, il faut donc se faire à l'idée qu'on ne maitrise qu'une partie du fonctionnement du bateau. «C'est une obligation à faire confiance ", relève un membre de l'équipage.

Le télégraphe scelle l'alliance entre les deux parties distinctes du bateau : le pilotage et la machine à vapeur. Chacune a son équipe, ses savoir-faire, ses espaces, ses uniformes, son vocabulaire, ses temporalités, mais leur collaboration est essentielle à la navigation. Le télégraphe permet non seulement leur communication, mais, en bon traducteur, il produit leurs interdépendances. 
Photo 2 : Le télégraphe dans la salle des machines

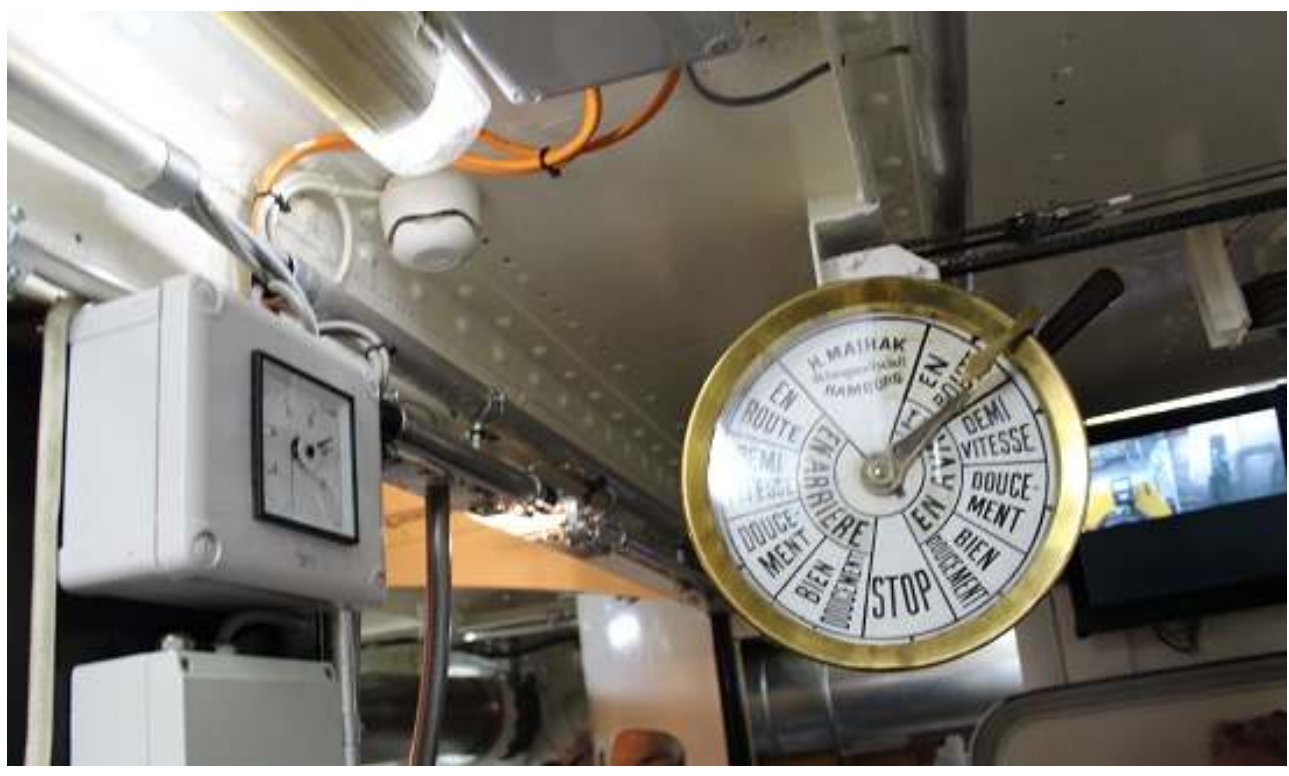

Source : Irina Radu

\section{BIBLIOGRAPHIE}

Latour, B. (2005), La science en action, Paris, La Découverte.

\section{NOTES}

1. Aussi surprenant que cela puisse paraitre, le télégraphe est toujours utilisé. Après avoir tenté de le remplacer par un dispositif électronique, la compagnie de navigation est finalement revenue à l'ancien système à la demande du personnel et suite à plusieurs incidents dus à une mauvaise communication entre le pilotage et la salle des machines.

\section{AUTEUR}

\section{LOÏC RIOM}

Doctorant au Centre de sociologie de l'innovation et chercheur associé à l'Institut de recherches sociologiques de l'Université de Genève. Ses travaux portent sur la musique, sa diffusion et sa valorisation. Il mène actuellement une thèse sur les secret shows. 